\title{
Correspondence
}

\section{The future of psychiatric care}

Sir: Dr Coid concludes his critique of the Clunis enquiry with depressing predictions about the future of psychiatric care (Psychiatric Bulletin, August 1994, 18, 449-452). He thinks the principles of the new guidance (care programme approach (CPA), register etc) are sound but that implementation will fail through lack of resources and lack of knowledge, training, and experience of mental health professionals in caring for the severely mentally ill in the community. Worse, he says that when a disaster does occur the finger of blame will be pointed at the responsible psychiatrist and key worker. He is right to warn. But it need not be like that.

The CPA and register are not just about good standards of care for individuals. Aggregated data from individual CPAs will tell health authorities, trust boards, and their chief executives precisely where there are gaps in service and what levels of risk their front-line staff are carrying. Thus a continuous and constructive dialogue can be fostered between mental health professionals, managers, and authorities, to share risk, give priority to the severely mentally ill, and target new resources.

Local authority social services have managed to create such a climate with child protection. Nowadays, it is the director of social services who faces the music when something goes wrong, rather than a front-line social worker. Not a single chief executive of health authority or trust that I have spoken to in London or elsewhere has disagreed that this is the kind of climate we need to create.

Things will not just remain bad if front-line staff fear scapegoating through the new guidance. Things will get much worse. There will be over-cautious decisions that waste resources. Mental health professionals will implement guidance to the letter, out of self-protection, rather than develop it creatively for their local population. Hence, Ministers and managers will not be encouraged to put in the substantial extra resource that is required because they will see nothing likely to deliver on the investment.

The single most important obstacle to improving the dire situations in some mental health services is the loss of heart by some of their psychiatrists. Health authorities and trusts have no alternative but to develop the relationship with clinicians. They must share the risks, not point the finger of blame. They must give clinicians the freedom to improve central guidance, not shackle them to rules. They must stimulate interest in successful services elsewhere, and in the question asked by Professor Tom Burns and others: when success ts achieved in establishing satisfactory care plans for previously uncooperative chronic and severely mentally ill patients what were the ingredients of the process that distinguished it from failed attempts?

Dr Coid seems to be viewing community care of the severely mentally ill through the keyhole of a locked door. There is much more going on that is effective than he appears to be able to see.

PETER KenNedy, Bootham Park Hospital, York YO3 7BY

\section{The at risk register}

Sir: The at risk register is not law, nor good practice, but it raises important ethical issues.

Physicians hold a position of trust within the community. Patients can turn to them for sympathetic understanding and confidential advice. The psychiatrist often becomes the only friend to those who find themselves alienated in a world perceived as uncaring and persecuting.

The policing role implied within the register is quite unacceptable. The psychiatrist is not a policeman nor a protector of society but a physician who operates within a carefully defined and well established ethical position, standing with the patient and offering support, confidentiality and asylum.

Of course we must recognise the concerns of government which have led to the introduction of the register and we should address these concerns. There are patients who need special provision in the interests of health, safety and for protection of others. This is provided by good psychiatric practice now called the care programme approach. Provision is also made through the Mental Health Act and it is this that should be extended as appropriate. Those detained or regulated have rights; a tribunal can hear their case; they may be represented by a solicitor; the Mental Health Act Commission ensures that they are being given proper care. Sufficient provision for asylum in whatever modern context is thought to be appropriate must be made. For our part, we must not collude with anything which threatens civil liberties, breaches confidentiality and places the responsibility on the physician alone.

For many years at the Annual General Meeting of the College, there was a motion of censure of 